\title{
Relation between size of delivery unit and neonatal death in low risk deliveries: population based study
}

\author{
Dag Moster, Rolv Terje Lie, Trond Markestad
}

\begin{abstract}
Aim-To examine risk of neonatal death after low risk pregnancies in relation to size of delivery units.

Methods-A population based study of live born singleton infants in Norway with birthweights of at least $2500 \mathrm{~g}$ was carried out. Antenatal risk factors were adjusted for.

Results-From 1972 to $1995,1.25$ million births fulfilled the criteria. The neonatal death rate was lowest for maternity units with 2001-3000 annual births and steadily increased with decreasing size of the maternity unit to around twice that for units with less than 100 births a year (odds ratio 2.1 ; $95 \%$ confidence interval 1.6 to 2.8). Institutions with more than 3000 deliveries a year also had a higher rate (odds ratio $1.7 ; 95 \%$ CI 1.4 to 2.0 ), but analyses suggest that this rate is overestimated.

Conclusion-Around 2000 to 3000 annual births are needed to reduce the risk of neonatal deaths after low risk deliveries. (Arch Dis Child Fetal Neonatal Ed 1999;80:F221-F225)
\end{abstract}

Keywords: maternity unit size; low risk delivery; neonatal mortality

There is no consensus on the optimal conditions for delivery after a normal pregnancy. On the one hand, well equipped hospitals are thought to be the safest place for all deliveries, as no antenatal screening procedure can guarantee an uncomplicated delivery. ${ }^{1-4}$ On the other hand, a delivery with no known risk factors may actually be put at risk by the increased medical attention of technologically advanced maternity units, and low risk deliveries may benefit from the minimal intervention approach in small maternity units. ${ }^{5-9}$

Since 1967 every birth in Norway has been registered in The Medical Birth Registry of Norway. This was specifically designed to evaluate maternal health, pregnancy complications, quality of delivery, place of birth, and health of the neonate. This dataset may be particularly relevant for studying the performance of different places of delivery for the following reasons: the Registry covers the entire birth population of one country for nearly three decades; it contains information on numerous factors related to adverse outcome and to place of birth; and the collection and content of data have remained the same during the study period. Furthermore, the national health care plan has consistently provided antenatal, intrapartum, and postnatal care free of charge. Deliveries have been performed at the local maternity unit unless identification of risk factors has suggested that a larger hospital might better be able to deal with any adverse outcome. In all types of institutions certified nurse-midwives have performed deliveries after low risk pregnancies.

Referral of women with known risk factors to larger maternity units makes it difficult to compare directly the crude mortalities among institutions. There are, however, ways of addressing this. First, all pregnancies with risk factors potentially detectable before birth can be excluded. Outcomes for the remaining pregnancies in the different types of institutions should then indicate how successful they were in avoiding and handling unexpected hazards during delivery. Although the smallest institutions should ideally handle only low risk women, most of the criteria for selecting such groups will exclude a significant number of women actually delivering at these institutions. A second strategy is therefore to compare the outcomes of all deliveries among institutions after adjustments for the proportion of women with various antenatal risk factors. This study aimed to use the data from the Medical Birth Registry of Norway to study neonatal mortality in relation to the size and expertise of the delivery unit using both of these strategies.

\section{Methods}

The Medical Birth Registry of Norway contains information on 1.7 million births between 1967 and 1995 with a gestational age of 16 completed weeks or more. Complete ascertainment of all births in the country is ensured through record linkage with the central population registry run by Statistics Norway. The distribution of reported risk factors was different for the first five years, 1967-71, compared with later years, due to inconsistent reporting when the programme was first being introduced. This period was therefore excluded, leaving 1.35 million births in the period 1972-95. Of this group, 1260777 were singleton live born infants with birthweights of at least $2500 \mathrm{~g}$, and 1254284 of these were registered as having been born in an institution.

For every woman we identified all conditions recorded in the registry that could have affected outcome and were potentially detectable before birth (table 1). Pregnancies without these factors were considered low risk. If the birthweight data were missing, only infants 
Table 1 Risk factors (\%) registered in Medical Birth Registry of Norway 1972-95 among deliveries of singleton live born infants with birthweights $\geqslant 2500 \mathrm{~g}$

\begin{tabular}{ll}
\hline Congenital malformations & 2.2 \\
Breech presentation & 2.7 \\
Transverse position & 0.1 \\
Placenta previa & 0.2 \\
Maternal age less than 18 years or more than & \\
$\quad 40$ years & 2.1 \\
Maternal disease before pregnancy† & 14.8 \\
Maternal disease during pregnancy $\ddagger$ & 18.2 \\
Four previous births or more & 2.0 \\
Gestational age of more than 42 weeks & 13.1 \\
Hydramnios or oligohydramnios & 1.0 \\
Premature rupture of membranes & 0.4 \\
Low risk deliveries $₫$ & 56.4 \\
Total number of infants & 1260777 \\
\end{tabular}

The percentages total more than $100 \%$ as some deliveries have more than one risk factor.

*All congenital anomalies except congenital dysplasia of the ^All con

†All reported maternal diseases before the start of pregnancy, except congenital dysplasia of the hips, allergic diseases, and urinary tract infections.

$\ddagger$ All reported maternal diseases with origin during the pregnancy potentially detectable before delivery, also including Rhesus immunisation.

\$Women aged 18 to 40 years, with no more than three previous births and no reported diseases before or during a singleton pregnancy, giving births within 42 weeks gestational age to an infant without any congenital anomalies and with a birthweight of $2500 \mathrm{~g}$ or more. There were no breech or transverse position, no prolonged ruptures of the membranes, transverse position, no prolonged ruptures
and no hydramnios or oligohydramnios.

with a gestational age of at least 37 weeks were included.

The neonatal mortality (the number of deaths within 28 days of a live birth divided by the number of live births) was selected as the primary outcome parameter. The Medical Birth Registry is regularly linked to the central population registry which holds independently collected information on all deaths in Norway, to ensure complete ascertainment of deaths. The stillbirth rate (the number of stillborn infants divided by the number of total births) was also calculated, to see how the inclusion of stillbirths would affect the main results, and also to permit comparisons with previous studies that have included stillbirths.

In Norway the level of medical care and size of maternity units are closely linked (fig 1). Even within the group of county hospitals obstetric, anaesthetic, and paediatric services, as well as equipment, are closely related to the size of the maternity unit. Outcome was therefore analysed according to the number of deliveries in the same year in the unit where the birth took place. The maternity units were grouped into sizes of no more than 100 births a year, 101-500, 501-1000, 1001-2000, 20013000 , and more than 3000 births a year. No institution had more than 5180 births in any year. If a mother was transferred from one institution to another during birth, the birth was registered at the institution where the infant actually was delivered, or excluded if the infant was born during transport. All home births were excluded.

In order to make the mothers who delivered at large and small centres comparable, the following two methods were used: we excluded all mothers having at least one of the conditions listed in table 1, leaving only the low risk mothers with no reported risk factors. For this subgroup, the relative risks of neonatal mortality between delivery units of different sizes

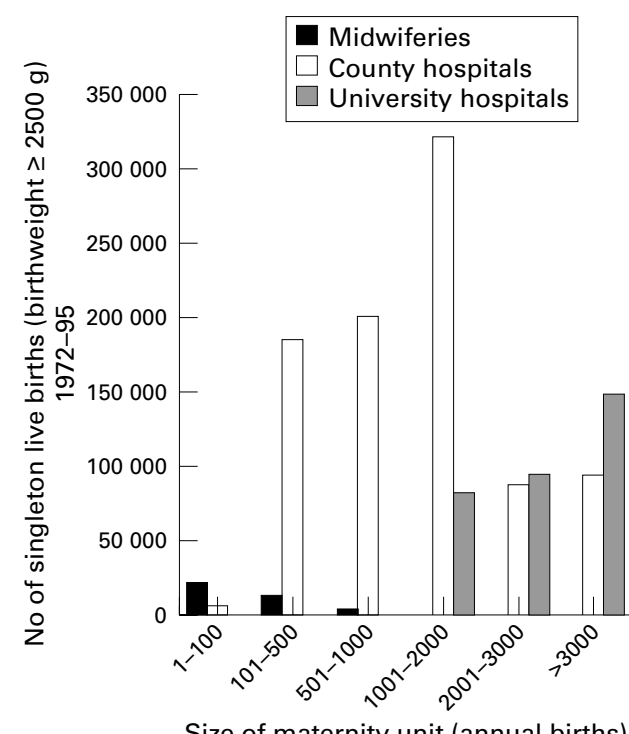

Figure 1 Association between level and size of delivery units.

were calculated by odds ratio in logistic regression models. Second, the same analyses were also performed after inclusion of all births, but with adjustments for the effects on the neonatal mortality for each condition listed in table 1 . This was done by including the conditions in the logistic regression model one at a time. After each step, continuing adjustment was done only for conditions shown to have significant effects on the neonatal mortality in the model. The sample size was thereby expanded from 700000 to 1.25 million births. Year of birth was used as a continuous variable, the other factors as categorical variables. The analyses were first restricted to birthweights of $2500 \mathrm{~g}$ or more but subsequently also expanded to $1500 \mathrm{~g}$ or more. Inclusion of even lower birthweights was avoided as the number of infants with very low birthweight was negligible in the smallest institutions, but contributed greatly to neonatal mortality in the largest ones.

As the neonatal mortality and stillbirth rates, as well as the proportion of deliveries occurring at institutions of different sizes, changed over time, adjustments were made for year of birth. To examine possible bias due to the large time span, all analyses were repeated separately for the cohorts $1972-77,1978-83,1984-89$ and 1990-95.

Both of the two strategies assumed that the maternity units adhered to the same criteria for reporting risk factors. To compare such practices, we used multivariate logistic models, with our definition of being at risk as the dependent variable. This was first done for all women delivering live born infants with birthweights of at least $2500 \mathrm{~g}$, and then for the women whose infants had died. BMDP Statistical Software was used for the statistical analyses. ${ }^{10}$

\section{Results}

During the period 1972 to 1995 , total neonatal mortality decreased from 7.7 to 3.5 per thousand live births and the stillbirth rate from 
Table 2 Relative risk $k^{\star}$ of neonatal death after a low risk deliveryt in maternity units of different size

\begin{tabular}{llll}
\hline $\begin{array}{l}\text { Size of } \\
\text { maternity unit } \\
\begin{array}{l}\text { No of births } \\
\text { peryear) }\end{array}\end{array}$ & $\begin{array}{l}\text { Low risk } \\
\text { deliveriest }\end{array}$ & $\begin{array}{l}\text { Relative } \\
\text { risk* }\end{array}$ & $\begin{array}{l}95 \% \\
\text { confidence } \\
\text { interval }\end{array}$ \\
\hline$\leqslant 100$ & 18053 & 1.8 & $1.1-3.1$ \\
$101-500$ & 119497 & 1.6 & $1.1-2.2$ \\
$501-1000$ & 117175 & 1.3 & $0.9-1.8$ \\
$1001-2000$ & 217524 & 1.5 & $1.1-2.1$ \\
$2001-3000$ & 98136 & 1.0 & ref. \\
$>3000$ & 136099 & 1.5 & $1.1-2.2$ \\
\hline
\end{tabular}

* Relative risks were approximated by odds ratios in logistic regression models adjusted for year of birth.

†Low risk delivery is defined as in table 1.

$\$$ There was an overall significant difference in mortality between maternity units with a $p$ value of 0.043

Table 3 Relative risk ${ }^{\star}$ of neonatal death among singleton infants with birthweights of at least $2500 \mathrm{~g}$ in maternity units of different size

\begin{tabular}{llll}
\hline $\begin{array}{l}\text { Size of maternity } \\
\text { unitt (No of } \\
\text { births per year) }\end{array}$ & Deliveries (n) & $\begin{array}{l}\text { Relative } \\
\text { risk }\end{array}$ & $\begin{array}{l}95 \% \\
\text { confidence } \\
\text { interval }\end{array}$ \\
\hline$\leqslant 100$ & 26486 & 2.1 & $1.6-2.8$ \\
$101-500$ & 197478 & 1.7 & $1.4-2.0$ \\
$501-1000$ & 203735 & 1.5 & $1.3-1.8$ \\
$1001-2000$ & 403506 & 1.5 & $1.3-1.8$ \\
$2001-3000$ & 181959 & 1.0 & ref. \\
$>3000$ & 241120 & 1.7 & $1.4-2.0$ \\
\hline
\end{tabular}

^Relative risks were approximated by odds ratios in logistic regression models adjusted for year of birth, congenital anomalies, maternal disease during pregnancy, breech presentation, multiparas, hydramnios or oligohydramnios, premature rupture of the membranes and placenta previa. premature rupture of the membranes and placenta previa.
+ There was an overall significant difference in mortality between maternity units with a $\mathrm{p}$ value of less than 0.0001

7.8 to 3.6 per thousand births, with a birthweight of at least $1000 \mathrm{~g}$. The neonatal mortality and stillbirth rates for infants born after low risk pregnancies decreased from 1.0 to 0.5 , and from 2.4 to 1.4 , respectively.

The maternity units with 2001 to 3000 annual births had the lowest neonatal mortality rate both when the low risk group was evaluated separately (table 2), and when the different risk factors were adjusted for in the whole cohort (table 3). Infants born at institutions with no more than 100 annual births had the highest risk for neonatal death. The risk declined with increasing size of the maternity unit until 2001 to 3000 annual births, and then increased for the largest institutions. The ranking between the units of different sizes was consistent for both methods of analyses, and was also consistent during the intermediate

Table 4 Relative risk ${ }^{*}$ of stillbirths and combined stillbirths and neonatal deaths among singleton infants with birthweights of at least $2500 \mathrm{~g}$ in maternity units of different size

\begin{tabular}{|c|c|c|c|}
\hline \multirow{2}{*}{$\begin{array}{l}\text { Size of maternity } \\
\text { unit (No of births } \\
\text { per year) }\end{array}$} & \multirow[b]{2}{*}{ Deliveries ( $n$ ) } & \multirow{2}{*}{$\begin{array}{l}\text { Stillbirthst } \\
\text { Relative risk* } \\
(95 \% \mathrm{CI})\end{array}$} & \multirow{2}{*}{$\begin{array}{l}\begin{array}{l}\text { Combined stillbirths } \\
\text { and neonatal deaths } \neq\end{array} \\
\text { Relative risk } \\
(95 \% \text { CI }\end{array}$} \\
\hline & & & \\
\hline$\leqslant 100$ & 26538 & $0.7(0.6-1.0)$ & $1.2(1.0-1.4)$ \\
\hline $101-500$ & 198030 & $1.0(0.9-1.2)$ & $1.3(1.1-1.4)$ \\
\hline $501-1000$ & 204261 & $1.0(0.9-1.1)$ & $1.2(1.1-1.3)$ \\
\hline $1001-2000$ & 404635 & $1.0(0.9-1.1)$ & $1.2(1.1-1.3)$ \\
\hline $2001-3000$ & 182437 & 1.0 (ref.) & 1.0 (ref.) \\
\hline$>3000$ & 241698 & $1.1(0.9-1.2)$ & $1.3(1.1-1.4)$ \\
\hline
\end{tabular}

$\star$ Relative risks were approximated by odds ratios in logistic regression models adjusted for year of birth, congenital anomalies, maternal disease during pregnancy, breech presentation, multiparas, hydramnios or oligohydramnios, premature rupture of the membranes and placenta previa.

tThere was not an overall significant difference in mortality between maternity units with a $p$ value of 0.17

$\ddagger$ There was an overall significant difference in mortality between maternity units with a $p$ value $\ddagger$ There was an overals
of less than 0.0001 . steps when the different risk factors were adjusted for in the logistic regression model. This was also true when birthweights of 1500 to $2499 \mathrm{~g}$ were included in the analyses.

Separate analyses for the smaller cohorts 1972-77, 1978-83, 1984-89 and 1990-95 had less statistical power, but the results were similar to those of the whole cohort. The proportion of unmarried mothers did not differ between institutions.

The relative risk of stillbirth was lower for institutions with less than 100 deliveries a year, but did not vary between larger institutions (table 4). The relative risk for combined stillbirths and neonatal deaths was lowest for institutions with 2001-3000 annual deliveries, but did not vary between the other institutions.

The proportion of pregnancies classified as at risk increased with increasing size of the maternity units up to 3000 annual births, but subsequently decreased significantly for institutions with more than 3000 deliveries. The same pattern with respect to risk factors was also demonstrated for the small group of women whose newborns died.

\section{Discussion}

The neonatal mortality rate for infants delivered after low risk pregnancies is extremely low irrespective of birth place compared with the total neonatal mortality (0.5 vs 3.5 per 1000 live births for infants born 1990-95). This underscores the need for large numbers in studies of low risk pregnancies. The reliability of a study also depends on how completely a large number of different biological risk factors are accounted for in the analyses.

Given the current low perinatal mortality, the stillbirth rate seems inappropriate as a measure of quality of delivery for the following reasons. First, most stillbirths occur before admission to the delivery unit, ${ }^{11}$ and do not reflect the unit's ability to avoid and handle complications during birth. Second, in Norway stillbirths before labour will be referred away from the smallest institutions for evaluation and induction. The present data underscore this policy as the smallest institutions had the lowest stillbirth rate. Given the low number of neonatal deaths, inclusion of stillbirths in the analyses would obscure differences in the outcomes of live born infants (table 4).

The exclusion of stillbirths might, however, still bias the comparison in favour of the smaller units, as fetal distress in a large unit will tend to result in emergency delivery and subsequent death for some of these infants, while the results might be stillbirth in small units. A higher incidence of intrapartum fetal death among low risk women with decreasing levels of available perinatal technology has been reported before. ${ }^{11-13}$

Our study may also be biased in favour of smaller units because in our Registry, the birthplace is registered as the place where the baby was finally delivered. A neonatal death after emergency transfer from a small maternity unit will therefore be registered at the largest hospital if the woman arrived at this 
hospital before delivery, or during transport if the neonatal death occurred before arrival.

The largest hospitals are located in the largest cities. A difference in risk of neonatal death between rural and urban areas due to social conditions might therefore bias the study. Information on marital status was the only parameter related to social conditions in the dataset. In Norway unmarried mothers are younger, less well educated, have lower socioeconomic status and have lower incomes than married women. ${ }^{14}$ The proportion of single mothers did not differ with size of institution, suggesting that differences in social conditions may not explain differences in outcome.

In this study we assumed that the reporting of risk factors to the Registry was similar from all types of institutions. We therefore expected larger and more sophisticated units to report a higher proportion of risk pregnancies. That the rate of pregnancies and neonatal deaths with recorded risk factors increased with the size of institution up to a size of 3000 births a year, was consistent with this assumption. However, the lower rate of recorded risk factors at the largest and most technologically advanced delivery units indicates that these units were less conscientious in reporting risk factors. The women with the most severe problems within the respective risk factors were also probably transferred to the largest institutions, making adjustments for these factors more difficult. The findings of higher neonatal mortality in the units with more than 3000 deliveries compared with the second largest institutions, may thus at least partly be a result of bias due to less complete registration of risk factors.

Although the increased neonatal mortality for institutions with more than 3000 annual births may be biased because of under reporting of risk factors, it is also conceivable that no further benefit is accomplished by increasing the size of the maternity unit beyond 3000 deliveries. Institutions with 2001-3000 annual births may be large enough to maintain a high level of expertise, and immediate access to rapid intervention and highly trained personnel such as anaesthesiologists and neonatologists. The largest units may be more difficult to organise and more focused on pregnancies and deliveries at very high risk. It should be noted that while the other categories consisted of fairly large numbers of hospitals, only six were represented in the category with more than 3000 annual births, and most of these have extensive teaching responsibilities.

A high throughput of patients and therefore increased physician and staff experience, improves the outcome for infants in need of neonatal intensive care and for many surgical procedures. ${ }^{15-17}$ Furthermore, studies have suggested that infants weighing less than $2500 \mathrm{~g}$ at birth have enhanced chances of survival in large obstetric units ${ }^{18-23}$ and in teaching hospitals. ${ }^{12}$ Several of these studies have, however, failed to show a benefit and some have even suggested an adverse effect on delivering infants with weighing over $2500 \mathrm{~g}$ at birth in large institutions. ${ }^{12} 18192123$ In our population the risk of neonatal death increased as the number of deliveries in an institution decreased below 2000 a year. In institutions with less than 100 annual births the risk was doubled. The true difference may even be greater as the possible biases most probably favoured the results from the smallest institutions.

Given the limitations of this study, it is reasonable to conclude that the experience, expertise, and equipment of larger institutions can also reduce the risk of neonatal death to a minimum for low risk deliveries.

We thank Professor Lorentz M Irgens at the Medical Birth Registry of Norway, Professor Rolv Skjærven at the Division for Medical Statistics, Department of Public Health and Primary Health Care, and Professor Torvid Kiserud at the Department Health Care, and Professor Torvid Kiserud at the Department
of Obstetrics and Gynaecology, Haukeland University Hospital, of Obstetrics and Gynaecology, Haukeland University Hospital, for advice during the initiation of this project, and Erik Lie-Nielsen for collaboration in making the database of the
Medical Birth Registry of Norway suitable for the analyses. This Medical Birth Registry of Norway suitable for the analyses. This
study was supported by a grant from the Norwegian Research Council.

1 Royal College of Obstetricians and Gynaecologists. Response to the report of the House of Commons Health Committee on to the report of the House of Commons Health

2 American Academy of Pediatrics, American College of Obstetricians and Gynecologists. AAP/ACOG. Guidelines for Perinatal Care. 3rd edn. Elk Grove Village: American Academy of Pediatrics, American College of Obstetricians and Gynecologists, 1992.

3 Sangala V, Dunster G, Bohin S, Osborne JP. Perinatal mortality rates in isolated general practitioner maternity units. BMF 1990;301:418-20.

4 Anonymous. [Editorial]. Home, hospital, or birthroom? Lancet 1986;ii:494-6.

5 Tew $M$. Do obstetric intranatal interventions make birth safer? Br F Obstet Gynaecol 1986;93:659-74.

6 Mathews J, Zadak K. The alternative birth movement in the United States: History and current status. Women \& Health 1991;17:39-56

7 Klein M, Reynolds JL, Boucher F, Malus M, Rosenberg E. Obstetrical practice and training in Canadian family medicine: Conserving an endangered species. Can Fam Physician 1984;30:2093-9.

8 Brody H, Thompson JR. The maximin strategy in modern obstetrics. F Fam Pract 1981;12:977-86.

9 Mengel MB, Phillips WR. The quality of obstetric care in family practice: are family physicians as safe as obstetricians? F Fam Pract 1987;24:159-64

10 Dixon WJ, ed. BMDP statistical software manual: 7.0 software release. Berkely: University Press of California, 1992.

11 Albers LL, Savitz DA. Hospital setting and fetal death during labor among women at low risk. Am 7 Obstet Gynecol 1991;164:868-73.

12 Cole SK, Macfarlane A. Safety and place of birth in Scotland. 7 Public Health Med 1995;17:17-24.

13 Hodnett ED. Alternative versus conventional delivery settings. In: Neilson JP, Crowther CA, Hodnett ED, Hofmeyr GJ, Keirse MJNC, eds. Pregnancy and Childbirth Module of The Cochrane Database of Systematic Reviews. Oxford: The Cochrane Collaboration, 1997:Issue 3.

14 Arntzen A, Moum T, Magnus P, Bakketeig LS. Marital status as a risk factor for fetal and infant mortality. Scand $\mathcal{F}$ Soc Med 1996;24:36-42.

15 Phibbs CS, Bronstein JM, Buxton E, Phibbs RH. The effects of patient volume and level of care at the hospital of birth on neonatal mortality. $\mathscr{f} A M A$ 1996;276:1054-9.

16 Luft HS, Bunker JP, Enthoven AC. Should operations be regionalized? The empirical relation between surgical volume and mortality. N Engl f Med 1979;301:1364-9.

17 Luft HS, Garnick DW, Mark DH, McPhee SJ. Hospital Volume, Physician Volume, and Patient Outcomes: Assessing the evidence. Ann Arbor, Michigan: Health Administration Press, 1990.

18 Hemminki E. Perinatal mortality distributed by type of hospital in the central district of Helsinki, Finland. Scand $\mathcal{F}$ Soc Med 1985;13:113-8.

19 Rosenblatt RA, Reinken J, Shoemack P. Is obstetrics safe in small hospitals? Evidence from New Zealand's regionalised perinatal system. Lancet 1985;ii:429-32.

20 Lumley J. The safety of small maternity hospitals in Victoria 1982-84. Community Health Stud 1988;12:386-93.

21 Paneth N, Kiely JL, Wallenstein S, Susser M. The choice of place of delivery. Effect of hospital level on mortality in all singleton births in New York City. Am $\mathcal{f}$ Dis Child 1987;141:60-4.

22 LeFevre M, Sanner L, Anderson S, Tsutakawa R. The relationship between neonatal mortality and hospital level. $\mathcal{f}$ Fam Pract 1992;35:259-64

23 Mayfield JA, Rosenblatt RA, Baldwin LM, Chu J, Logerfo JP. The relation of obstetrical volume and nursery level to perinatal mortality. Am f Public Health 1990;80:819-23. 


\section{Commentary}

It is generally agreed that centralisation of obstetric services is essential to improve perinatal outcomes in high risk pregnancies. But does this apply to low risk pregnancies? The Norwegian study examines the relation between size of maternity unit and neonatal mortality. It concludes that hospitals delivering fewer than 100 babies a year show a twofold increase in risk of death in a low risk pregnancy.

Can these findings be extrapolated to the UK? Here, debate on the safety and place of delivery has centred on planned home births. In 1967 around one in five babies were delivered at home in England and Wales. This has declined to less than $1 \%$ in the 1980 s and is now around $2 \%$. Similar declines have been seen in numbers delivering in isolated general practitioner units (less than $2 \%$ ). The statistical pitfalls discussed by the Norwegian authors have featured in this debate: differences in case mix; imprecise assessment of rare outcomes; and how to deal with transfer of cases.

It is now no longer possible to undertake a randomised controlled trial in the UK, and the biases inherent in retrospective data analysis preclude a conclusive answer to these questions. The problem continues to be tantalisingly elusive.

Director, Confidential Enquiry into

MARY MACKINTOSH Stillbirths and Deaths in Infancy

Chiltern Court, 188 Baker St

London NW1 5SD 